\title{
Multivariate Process InCAPABILITy IndeX FOR NON-NORMAL DATA: A CASE STUDY
}

\author{
CAsalino, G. \& Rotondo, A.
}

Abstract: When several quality characteristics have to be considered in process capability analysis, conventional indices are difficultly applicable. Above all when different processes have to be compared in terms of capability, they rarely univocally express which process can be considered the best one. Moreover, conventional process capability indices (PCIs) separately consider quality characteristics regardless of eventual mutual dependencies existing between them. In order to offset these weaknesses, useful tools are the multivariate capability indices. In this study, based on the non-normal Cpp formulation, the multivariate process incapability index for non-normal data, MCpp(q), is proposed. The non-normal Cpp has been constructed using Clements' method; however, Burr XII distribution has been used in place of the Pearson distributions family for assessing non-normal percentiles. The bootstrap methodology has been used to draw an interval estimate of the index proposed. A case study on the comparison between two different cold extrusion processes has been presented to demonstrate how the proposed index can be applied to real data.

Key words: Process Incapability Index, Principal Component Analysis, Multivariate Process Capability Indices, Burr type XII distribution, Bootstrap methodology
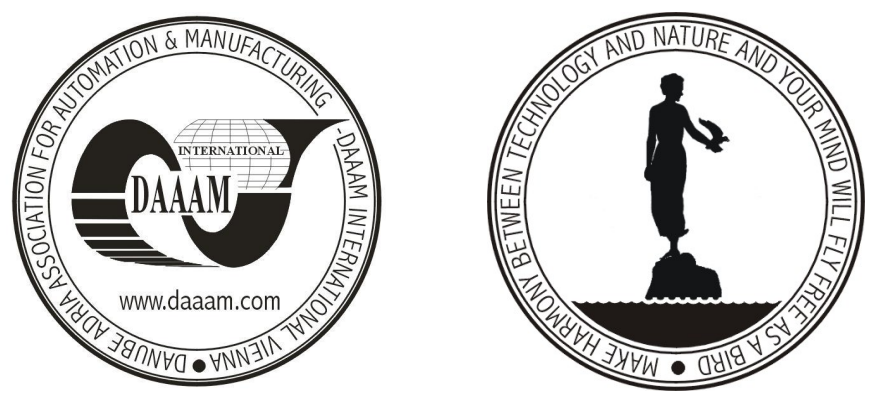

Authors' data: Ph.D. Prof.Casalino, G[iuseppe]; Ph.D. student Rotondo, A[nna], Politecnico di Bari, Viale Iapigia, 186, 70126 Bari, Italy, g.casalino@poliba.it, a.rotondo@poliba.it

This Publication has to be referred as: Casalino, G. \& Rotondo, A. (2007). Multivariate Process Incapability Index for Non-Normal Data: A Case Study, Chapter 07 in DAAAM International Scientific Book 2007, B. Katalinic (Ed.), Published by DAAAM International, ISBN 3-901509-60-7, ISSN 1726-9687, Vienna, Austria DOI: $10.2507 /$ daaam.scibook.2007.07 